\title{
RELATO DE EXPERIÊNCIA NA FORMAÇÃO DA IDENTIDADE DOCENTE
}

Experience Report in the Formation of the Teaching Identity

Informe de Experiencia en la Formación de la Identidad Docente

Kassia Oliveira da Silva ${ }^{1 *}$, Eduardo Barros ${ }^{1}$, Shirlley Melo da Luz Santos ${ }^{1}$, Edgar Duarte da Silva ${ }^{2}$ Érica Cupertino Gomes ${ }^{1}$

${ }^{1}$ Curso de Licenciatura em Física, Universidade Federal do Tocantins, Araguaína - TO, Brasil

${ }^{2}$ Colégio Pré-Universitário de Araguaína, Araguaína - TO, Brasil

*Correspondência: e-mail kassiamartinsoliveira@gmail.com

\section{INTRODUÇÃO}

Métodos de ensino são assuntos abordados em diversos ramos da licenciatura, com o objetivo de instigar professores a realizarem estudos contínuos para o aprimoramento e enriquecimento da prática pedagógica em sala de aula, ocasionando mudanças na atividade docente. Em vista disso, a Universidade Federal do Tocantins busca alternativas com o programa para os alunos praticarem aprenderem métodos de ensino já em sua formação acadêmica.

Atualmente os programas institucionais como o Programa de Apoio ao Discente Ingressantes (PADI), o Programa Institucional de Monitoria (PIM), o Programa Institucional de Bolsas de Iniciação à Docência (PIBID), e a Residência Pedagógica (RP), estão disponibilizados na Universidade Federal do Tocantins (UFT) e dentre outras universidades que possuem cursos de licenciatura. Tais programas visam o desenvolvimento na formação profissional dos discentes, mas cada um com sua objetividade.

O PADI e o PIM, oportunizam aos discentes tutores o enriquecimento técnico, pessoal e profissional, através das tutorias e da produção de atividades acadêmicas de caráter didático-pedagógico para outros discentes com dificuldades em disciplinas do curso, além de assumir outras responsabilidades do âmbito acadêmico.

Para proporcionar aos estudantes de licenciatura uma experiência no cotidiano escolar, por iniciativa do MEC, a Capes criou o Programa Institucional de Iniciação à Docência (PIBID), com o propósito de possibilitar a harmonização entre a teoria e a prática, para o aprimoramento da formação docente e elevar o padrão de qualidade da educação básica, mediante a articulação ensino, pesquisa e extensão e do envolvimento da escola e da universidade (CASTRO, 2016). Seguindo essa narrativa, pode-se considerar que, a Residência Pedagógica se apresenta como um novo programa englobando a parte pedagógica e profissional.

Financiado pela Capes, o Programa de Residência Pedagógica tem como principal objetivo melhorar e fortalecer o desenvolvimento profissional dos futuros professores usando como ferramenta a vivencia no âmbito escolar, proporcionando aos estudantes de licenciatura, que já estão no período de estágios obrigatórios, uma integração melhor entre a teoria e prática, permitindo-os evoluírem através de experiências nas escolas púbicas. Visto que, as experiências adquiridas no decorrer do programa, 
proporcionam aos residentes uma reflexão sobre a realidade do ensino e aprendizagem na educação, possibilita aplicações de novas práticas docentes, e assim estimula a sua criatividade e inovação.

O programa de residência pedagógica vem buscando o aprimoramento da formação docente por meio da necessária articulação entre o que os alunos aprendem na universidade e o que experimentam na prática da residência (CASTRO, 2016).

No Programa Residência Pedagógica, os discentes são acompanhados pelo professor preceptor, que realiza reuniões periódicas para debater assuntos, sanar dúvidas e compartilhar experiências vivenciadas no âmbito escolar, proporcionando para os residentes um momento de articulação e reflexão da atividade docente, e uma interação na troca de saberes entre os residentes.

\section{METODOLOGIAS E MATERIAIS}

A experiência na RP desenvolveu-se no Colégio Estadual Pré-Universitário de Araguaína no âmbito do subprojeto do curso de Física, focalizando na ambientação escolar, observação, análise e intervenção na sala de aula. Todas essas etapas foram fundamentais para realização do programa na escolacampo.

Com a experiência obtida por meio das observações em sala de aula, foi possível questionar e refletir sobre o trabalho docente administrativo, a prática do professor, intervir na sala e o processo de ensino, além de identificar os alunos, os problemas e dificuldades que têm na aprendizagem.

Segundo a equipe pedagógica da escola, a unidade escolar tem projetos que objetivam buscar ações voltadas para a melhoria do desempenho escolar dos alunos. Em virtude disso, foi discutido a organização administrativa escolar, bem como a linha metodológica e pedagógica, os seguimentos de normativas e os regimentos educacionais.

Debateu-se também a construção profissional dos professores e como os residentes poderiam aprender o máximo possível com as etapas do programa. Diante das perspectivas da formação docente, foram esclarecidos, para os residentes, a interrelação dirigidas em aprender e ensinar desafiando as concepções prévias da aprendizagem, encorajando uma construção de conhecimento.

No Colégio Pré-Universitário, vivenciamos algumas ações pedagógicas, uma delas foi a gincana que envolveu todos os alunos. A equipe pedagógica da escola teve participação total na elaboração do planejamento e atuamos como equipe de apoio. Cada turma foi dividida em quatro grupos, cada grupo representado por uma cor (verde, amarelo, azul e vermelho), os grupos tiveram que trabalhar em equipe para arrecadar alimentos não perecíveis, roupas e calçados. A participação dos pais foi indispensável e permitiu a promoção do aumento da relação entre pais e filhos.

Na escola houve um conselho de classe no qual os residentes participaram, e a participação nos fez vivenciar diversas decisões tomadas pelos professores e coordenadores referentes aos alunos que apresentaram rendimento abaixo da média, os que exibiram comportamentos inaceitáveis e aos que possuem algum tipo de problema pessoal que interferiu no desempenho escolar.

\section{RESULTADOS E DISCUSSÃO}

A aprendizagem é uma formação que modifica a relação do sujeito com mundo, mediante a experiência. No início das atividades da RP na escola, as expectativas eram bastante diferentes em relação a 
realidade presenciada, o respeito ao espaço escolar, os recursos disponíveis e os desafios. Após a realização da residência pode-se ter uma visão bem ampla da rotina escolar e do sistema administrativo. Com as experiências obtidas no programa Residência Pedagógica, compreendemos que a educação de qualidade exige uma equipe unida e colaborativa, para levantar a autoestima e o interesse de todos. E neste contexto, cada um contribui com a sua criatividade, resolvendo problemas em sala de aula, criando ambiente favorável para ajudar no aprendizado dos alunos, buscando investimentos como instrumentos didáticos, estrutura escolar dentre outros.

Com a experiência obtida também na gincana com os alunos e na participação no concelho de classe da escola, foi possível integrar os conhecimentos e interagir com a dinâmica escolar, debatendo sempre, com os professores da escola, sobre como superar os desafios da profissão. Com as observações, as pesquisas, e os estudos realizados no programa, dispomos de concepções e perspectivas mais detalhadas sobre as qualificações e contribuições necessárias para o ensino, uma conscientização para a determinação, comprometimento, responsabilidade e preparo da nossa futura profissão.

Em conformidade com Pannuti (2015), percebemos que um dos aspectos mais complexos da formação de professores consiste em proporcionar experiências por meio das quais eles possam integrar seus conhecimentos, articulando-os na prática docente; o sujeito da experiência deve ser definido por sua receptividade, por sua abertura, por sua disponibilidade, sendo que a experiência promove formação e transformação.

\section{CONCLUSÃO}

A Residência Pedagógica requer que os residentes sejam organizados e bem instruídos para conviver com os alunos, em razão da profissão como professor. Haverá ocasiões que terão que problematizar situações inesperadas e apresentar soluções ou alternativas possíveis. Todavia, a formação teórica juntamente com a prática ocasiona diversas experiências, ao longo da vivência no ambiente escolar, além de ajudar na transformação de um acadêmico em um professor pesquisador e inovador, atribuindo-o várias outras habilidades e competências.

\section{AGRADECIMENTO}

Agradeço a Deus, à Capes por patrocinar o Programa Residência Pedagógica, a Universidade Federal do Tocantins, à Coordenadora Prof ${ }^{a}$. Dr ${ }^{a}$ Érica Cupertino Gomes, o Orientador Prof. Dr Matheus Pereira Lobo, e o Supervisor Prof. Ms. Edgar Duarte da Silva pelos ensinamentos durante o programa.

Todos os autores declararam não haver qualquer potencial conflito de interesses referente a este artigo.

\section{REFERÊNCIAS}

CASTRO, C.N.L, Residência Pedagógica: Representação Sociais de Formação Continuada. 2016. Tese em Educação, Universidade Estácio de Sá. Rio de Janeiro, 2016

PANNUTI, M.P. A Relação Teoria e Prática na Residência Pedagógica. EDUCERE, XII Congresso Nacional em Educação. Curitiba- PR, 2015. 